\title{
Digitalization of the construction products' manufacturing process as a guarantee of the finished products quality
}

\author{
Elena Romanenko*, Valeria Kim, and Alexey Sandul \\ Don State Technical University, 344000, Rostov-on-Don, Russia
}

\begin{abstract}
The article highlights the problems associated with the quality of the information platform at the enterprise, which is the guarantor of the quality of products and structures manufactured at the enterprises of the reinforced concrete complex. The article substantiates the dependence of the finished product quality parameters on the processes' digitalization and the increase in the enterprise efficiency through the business information processes introduction in the WEB-segment. An example is given of integrating contextual advertising into the marketing sphere of an enterprise that manufactures the products for construction purposes and the implementation of the Bitrix24 system, which can be one of the most important tools in organizing the work of an enterprise through those aspects of the company that it can cover, starting with the coordination of the employees' work, planning, analysis and administrative control as well as the economic activities of the enterprise and ending with document flow.
\end{abstract}

\section{Introduction}

The objective reality today is the widespread digitalization introduction in all spheres of life of a modern person. The term "digital economy" can be heard more and more often.

At its core, the "digital" (electronic) economy is an economic activity in which the key production factor is digital data, the processing of large volumes and the use of the analysis results of which, in comparison with the traditional forms of management, can significantly increase the efficiency of various types of production [1]. Or, in other words, "digital" (electronic) economy is an economy that exists in a hybrid world.

The study of this problem makes it possible to note that digitalization will penetrate into all spheres of society more actively every year as a phenomenon.

Digitalization use at an enterprise changes both the external and internal space of the organization: interaction with the state, suppliers and consumers, the organization of internal processes of activity, including in the field of management.

Digitalization is an undoubted trend in the economic life of modern society. There are several definitions of this term. However, from our point of view, in relation to enterprises in the construction industry, it is most expedient to consider digitalization as a systematic

\footnotetext{
* Corresponding author: Romanenko-RGSU@mail.ru
} 
approach to using digital resources to increase labor productivity, competitiveness and economic development in general.

The digital economy as a type of economic activity is distinguished by the fact that an increase in the production efficiency leads to an increase in the efficiency of technologies, equipment, storage, sale, delivery of goods and services [2].

There are different approaches which can exactly be attributed to the main digitalization technologies. Analysis of six key technologies [3] that are critical for modern digital transformation includes: mobile technologies, cloud computing, big data, business analytics, social networks, artificial intelligence, showed the most promising opportunities for the information base of social networks.

\section{Analysis of the problem, goals and objectives of the work}

The problem of finding a target audience in the construction segment market is one of the most important in terms of the functioning of an enterprise in conditions of fair competition. This problem is partially solved by searching and collecting a client base through offline resources (outdoor banners, signs, etc.) and online advertising channels that have become available relatively recently. However, this problem is not new and has been highlighted by a number of authors from the point of view of the cloud services expediency, privacy in social networks, outsourcing and relationships with the customer base through social networks [4-7].

Let us consider the concept of "online advertising", or more precisely, contextual advertising, from the point of view of its effective functioning in the field of the construction segment. Contextual advertising is a type of Internet advertising in which an advertisement is displayed in accordance with the content, selected audience, place, time or other context of Internet pages.

Investigating the problems of integrating contextual advertising into the marketing activities of an enterprise, it was revealed that the greatest effect is achieved with the combined use of methods of logical and statistical analyzes, as well as practical data obtained as a result of the development and implementation of Internet advertising certain aspects.

Hence, the first goal that needs to be solved is a comprehensive authors' study of the problem of integrating contextual advertising into the marketing sphere of an enterprise that manufactures the products for construction purposes. Search and optimization of suitable tools for the implementation of the set business objectives, elaboration and development of a long-term perspective of cooperation with a client

Simultaneously with the external problems, the chaotically changing economic situation in the consumer market requires from the organizations to make operational decisions in order to update work within the company under external conditions.

The current unstable economic situation in the country and the world at the beginning of 2021, caused by quarantine measures to combat the epidemic, has led to the fact that more and more companies are switching to a remote work format, but this requires optimization of the work of employees of organizations. When asked how to connect employees working remotely with employees in the office, clients and management, the following option should be considered - the implementation of a set of measures for intra-organizational optimization, which are based on the Bitrix 24 system [8].

In making operational decisions and optimizing the organization's work, the solution of the following urgent problem will help, namely, the implementation of Bitrix 24 through a comprehensive author's study of the problems of increasing the efficiency of a construction organization through the introduction of business information processes in the WEBsegment; search and optimization of suitable tools for the implementation of the assigned 
internal organizational tasks; elaboration and synchronization of all parts of the enterprise's labor activity in a single information environment.

As it was repeatedly noted in the early works of the authors $[9,10]$, the enterprises' competitiveness in the construction complex at the present stage of production capacities development is impossible without the widespread introduction of technological innovations into the production process. In general, innovations in one form or another are present at all enterprises of the construction complex, however, their effectiveness for each enterprise is ambiguous and, as a result, a different level of competitiveness of the products of these enterprises in the sales market is formed.

The most effective innovative step at the moment should be considered the active digitalization of production processes and the transfer of the maximum amount of internal and external information to digital platforms.

In other words, digitalization of the processes associated with the construction complex enterprises' main activity implementation - the release of finished products - will provide building materials, products and structures with the quality parameters required by the consumer.

\section{Research part, recommendations for manufacturing enterprises}

A further step in increasing production efficiency is to consider the process of business processes digitalization, which consists in the transition of an enterprise to electronic platforms. Digitalization of business processes gives an opportunity to reduce the number of steps required to complete a specific task, reduces the amount of work with documents and the influence of the human factor. In the future, digital transformation provides for a qualitative change in the entire business model, from the enterprise strategy to the production processes digitalization.

An analysis of its significance for increasing the production activities efficiency will be carried out on the example of an enterprise that manufactures products for construction purposes.

The enterprise, on the example of which the integration effectiveness of this tool will be considered, is engaged in the production of reinforced concrete products.

The basis in ensuring the quality of finished products at the enterprises of the construction complex are reliable suppliers of raw materials.

As noted earlier [11, 12], the search for suppliers is a rather complicated and problematic process. The difficulty lies in the reluctance of individual manufacturers to expand the circle of their consumers (existing consumers are completely satisfied with the quality of products and the sale is carried out in full production), on the one hand, there are unscrupulous suppliers who advertise their products initially not corresponding to the truth with quality parameters. In both cases, the consumer suffers, i.e., the enterprise for the production of products based on concrete mixtures.

To exclude such phenomena, the company decided to create an information platform.

The created information platform will make it possible not only to track manufacturers producing products of the required quality parameters, but also to monitor the feedback from other consumers on the stability of the product quality parameters declared by the supplier.

How is contextual advertising implemented?

The main problem faced by the company is the lack of targeted traffic, which in turn leads to such consequences as: a decrease in the volume of products sold, an increase in advertising costs, uncompetitiveness, stagnation of the company in the construction 
services market, etc., therefore it is necessary to take an emergency decision to introduce contextual advertising.

The implementation stages included the following goals and objectives: studying a niche and competitors - setting up contextual advertising in Yandex, Direct and Google Adwords advertising offices - collecting a semantic core-support, analyzing statistical data, testing and developing marketing hypotheses.

Analysis of the competitors' niches, selection of requests suitable for the technology under consideration (suppose the supply of inert aggregates for concrete mix 5-20 mm fr.): strength characteristics and frost resistance of crushed stone, pricing policy, purity of the manufactured product, delivery method performed during the semantic core development, as well as setting up contextual advertising on Yandex and Google gave a positive result already in the first month of cooperation - orders for the supply of crushed stone on the basis of long-term contractual relations. After making changes related to adjusting the advertising campaign in Yandex, Direct and Google Adwords, the indicators of the enterprises' economic activity, both suppliers and consumers, began to grow steadily.

The considered example of the results achieved is proof of the fact that online advertising, and in particular the "context", can be a very powerful tool for fair competition in the construction industry market, and every year these mechanisms are becoming more and more advisory in nature.

But the overall success of the enterprise production activity depends not only on the external conditions of the market, but also on the enterprise internal processes.

As already noted, in modern conditions, it is most effective to carry out intraorganizational optimization using the Bitrix 24 system.

Work on the Bitrix 24 system implementation is a step-by-step process: comprehensive authors' studies of the problem of increasing the efficiency of the enterprise through the introduction of business information processes in the WEB-segment; search and optimization of suitable tools for the implementation of the assigned internal organizational tasks; elaboration and synchronization of all parts of the enterprise labor activity in a single information environment. In the process of researching the problem of increasing the efficiency of an enterprise producing products for construction purposes, through the introduction of business information processes in the WEB segment, the methods of logical and deductive analysis were used.

The final result of this tool implementation is the optimization of all life cycles and information processes of the enterprise in a single web space, the solution of a wide range of tasks related to time management, workflow, deadlines and communication between employees and clients.

Bitrix 24 is an online platform that is a closed network that gives a possibility to coordinate: document flow, corporate communications, assignment of tasks and priorities for both enterprise employees and managers, stages of processing the client base and deadlines for completing tasks. Also, this platform contains cloud storage that makes it possible to store large volumes of commercial information.

Specific optimization aspects in which this platform helps:

- Online office:

- This tool helps the leader to build effective work in his team. Coordination of remote employees and partners.

- Office work and document flow:

- $\quad$ by setting up a sales funnel, the system will automatically convert leads into deals, and thanks to integration with $1 \mathrm{C}$, it will keep track of the inventory balance and keep some of the bookkeeping. Implementation result: acceleration of document flow, reduction of workload on staff, prevention of errors in documentation. Also, Bitrix 24 has a smart calendar that calculates the working hours of specialists and their work schedule. 
- Full control of the entire sales cycle and work with clients.

- Secure storage for all documents:

- $\quad$ secure cloud storage Bitrix.Disk, connected to the corporate portal, gives an opportunity to solve all the problems of the enterprise at once. Uploading files to the cloud makes it possible to develop a convenient documentation structure and provide access to individual zones for specific employees. At the same time, the use of the cloud gives a possibility to conveniently work with documentation, access to the access system and SSL encryption - to prevent leakage of confidential data.

- Planning and analytics:

- time management and organization of work of employees using the calendar and the section "Tasks and Projects" - the basis for the effective work of an enterprise of any size. In addition, through CRM analytics and reports, statistical data that allow for an audit and analysis of the entire structure of the company are collected. Thanks to this, problem areas can be identified in a timely manner and a strategy and action plan for development and promotion can be developed.

The implementation of Bitrix 24 will give an opportunity to fully control the administrative and economic activities of the enterprise. And also receive all the necessary data for analysis and time management.

Modern requirements for industrial complexes for the manufacturing of reinforced concrete products and structures is the introduction of automation of individual technological processes. And this is fully justified, since in this case the human factor is removed from the general technological chain of production processes that ensure the products quality.

The implementation of the basic requirements for ensuring the quality parameters of finished products for the construction purposes has been worked out in a comprehensive program for introducing digitalization into the business process organization system.

Implementation of automatic control systems for the preparation of concrete mix with programmed control using software, automatic control of the operating mode of a heating unit that carries out heat and moisture treatment of fresh formed reinforced concrete products, automation of the manufacturing process of reinforcing products significantly increases the stability of the quality parameters of manufactured reinforced concrete products, while allowing information to be accumulated in digital databases and thereby allow volumetric analysis of the results of the entire technological process, excluding to the maximum all bottlenecks in the production cycle.

And if at the same time we exclude all types of blunders and mistakes that are made by representatives of other production links related to the non-production sphere (supply system, sales, office work, services of the chief technologist, chief power engineer and other services) from non-production losses, then on the basis of excluding them from the total volume of costs that form the production cost, the enterprise will increase its own competitiveness not only in terms of ensuring the stable quality parameters of finished products, but also in terms of increasing the purchasing power of consumers by reducing the selling cost of finished products.

\section{Conclusion}

Analyzing the above-said, we can conclude that by introducing information platforms into the production system for construction products, within the framework of digitalization and business process reorganization for the manufacture of construction products, it is possible to transfer an enterprise from the category of assessing the quality of finished products to the category of manufacturing products with established quality parameters and controlled parameters of the business process. 
At the same time, transferring the technological processes management and assessing the finished products quality to an electronic platform will significantly improve the production culture of the enterprise, identify the causes of defects and improve the quality of construction products.

At the same time, the implementation of the Bitrix 24 system may turn out to be one of the most important tools in organizing the work of enterprises producing materials, products and structures for construction purposes through the aspects that it can cover, starting with the coordination of the work of employees (working both in a remote format, including outsourcing, and directly at the conditions of the enterprise) and ending with document flow.

\section{References}

1. Decree of the President of the Russian Federation of May 9, 2017 No. 203 "On the Strategy for the Information Society Development in the Russian Federation for 2017 2030".

2. Strategy for the information society development in the Russian Federation for 20172030. Approved by the Decree of the President of the Russian Federation. No. 203 dated May 9, 2017 [Electronic resource]. http://kremlin.ru/acts/bank/41919 (application date: 02.02.2020).

3. N.Yu. Konina, Management problems of the world's largest companies in the context of digital transformation, «Neftegaz.ru». 7(79), (2018). [Electronic resource]. - Access mode: $\quad$ https://magazine.neftegaz.ru/articles/avtomatizatsiya/523698problemymenedzhmenta-krupneyshikh-mirovykh-firm-v-usloviyakh-tsifrovoytransformatsii/ (Electronic resource]. - Access mode: 02.02.2020).

4. M.C. Lacity and L.P. Willcocks, Advanced Outsourcing Practice: Rethinking ITO, BPO, and Cloud Services (Palgrave, London, 2012).

5. V. Kumar and R. Mirchandani, "Increasing the ROI of Social Media Marketing," MIT Sloan Management Review 54 1, 55-61 (fall 2012) and M. Mount and M. Garcia Martinez, "Rejuvenating a Brand Through Social Media," MIT Sloan Management Review 55 4, 14-16. (summer 2014)

6. C. Heller Baird and G. Parasnis, "From Social Media to Social Customer Relationship Management," Strategy \& Leadership 39. 5, 30-37 (2011)

7. P. Sánchez Abril, A. Levin, and A. Del Riego, American Business Law Journal 49. 1, 63-124 (spring 2012)

8. Information on www.bitrix24.ru

9. E.Yu. Romanenko, A.S. Ryabichenko, Bulletin of the Moscow State Regional University. Series: Economics 2, 172-180 (2018)

10. E Romanenko, S Ryabichenko, IOP Conf. Ser.: Mater. Sci. Eng. 698, 022074 (2019)

11. E Yu Romanenko, A V Nalimova, IOP Conf. Series: Materials Science and Engineering 913, (2020) 032044 doi:10.1088/1757-899X/913/3/032044.

12. E Yu Romanenko, N V Vodolazskaya, IOP Conf. Series: Materials Science and Engineering 1083012055 (2021) doi.org/10.1088/1757-899X/1083/1/012055 